\title{
Orbicularis oculi reflex in coma: clinical, electrophysiological, and pathological correlations ${ }^{1}$
}

\author{
LYNN W. LYON, JUN KIMURA, ${ }^{2}$ AND WILliaM F. MCCORMICK ${ }^{3}$ \\ From the Departments of Neurology (Neurosensory Center) and Pathology \\ (Division of Neuropathology), College of Medicine, University of Iowa, Iowa City, U.S.A.
}

SUMMARY The orbicularis oculi reflex was studied in 48 comatose patients and the results werec correlated with clinical and pathological findings. The late component of the reflex was absent or of minimal amplitude in all cases regardless of the site of lesions, reflecting a diffuse suppression of theon reticular system rather than a specific or local block in the brain-stem. Alteration of the early component of the reflex, on the other hand, generally indicated primary or secondary structural changes. in the pons, although reversible functional or pharmacological block of pontine conduction was alsow documented.

Kugelberg (1952), using glabellar tap stimulation, first demonstrated two separate components of the orbicularis oculi reflex: an early ipsilateral reflex and a late bilateral reflex. Rushworth (1962) and Gandiglio and Fra (1967) subsequently showed that electrical stimulation of the supraorbital nerve also evokes an early ipsilateral and a late bilateral reflex in the orbicularis oculi muscle. Standardization of the latter technique by Bender, Maynard, and Hastings (1969) and by Kimura, Powers, and Van Allen (1969) has led to its clinical application in the evaluation of lesions of the facial (Bender et al., 1969; Kimura et al., 1969) and trigeminal nerves (Kimura, Rodnitzky, and Van Allen, 1970) and in polyneuropathy (Kimura, 1971). Subsequent studies have demonstrated central delay of the orbicularis oculi reflex arcs in multiple sclerosis (Kimura, 1970; Namerow and Etemadi, 1970), brain-stem neoplasms and syringes (Kimura and Lyon, 1972), and vascular lesions of the brainstem (Kimura, 1971; Kimura and Lyon, 1972).

Although it is clear that the trigeminal and

\footnotetext{
1 The Neurosensory Center is supported by Program-Project Grant No. NS03354 of the National Institute of Neurological Diseases and Stroke, Bethesda, Maryland. Neurosensory Center Publication No. 219.

2 Present address: Department of Medicine (Neurology), University of Manitoba, and the Department of EEG, Winnipeg General Hospital, Winnipeg, Manitoba.

3 Reprint requests: Dr. McCormick, Division of Neuropathology, University Hospitals, Iowa City, Iowa 52240, U.S.A.
}

facial nerves are the afferent and efferent limbs respectively, the nature of the central conne tions of the early and late reflexes remains ư⿴囗十 known. The early ipsilateral component wos을 initially considered to be a monosynaptic pro- $-\overrightarrow{0}$ prioceptive reflex (Kugelberg, 1952). Tokunagy, Oka, Murao, Yokoi, Okumura, Hirata, Miyg-응 shita, and Yoshitatsu (1958), however, demo strated in cats that selective destructive lesions the main sensory trigeminal nucleus abolished the early ipsilateral reflex, while no change waso affected with lesions of the mesencephalic trigeminal nuclei. Shahani (1970) has suggested a⿳亠二口犬 probable cutaneous nature of the early reflex.0ั The bilateral late component is considered to be nociceptive in nature and is probably transmitted $\overrightarrow{\hat{O}}$ through a multisynaptic reflex arc including the 3 spinal tract and nucleus of the trigeminal nerve (Kugelberg, 1952; Tokunaga et al., 1958; Rushworth, 1962; Gandiglio and Fra, 1967).

Investigation of the orbicularis oculi reflex in coma is the subject of this report.

\section{METHODS}

Methods for studying the orbicularis oculi reflex ando normal latency values (Table) have previously been $>$ reported by Kimura et al. (1969). The facial nerve is stimulated just anterior to the mastoid process eliciting the direct motor response of the orbicularis. oculi muscle (Fig. 1). The supraorbital nerve is then 
TABLE

ALTERATION OF THE ORBICULARIS OCULI REFLEX IN 48 CASES OF COMA

\begin{tabular}{|c|c|c|c|c|}
\hline & \multirow[t]{2}{*}{ Cases } & \multicolumn{2}{|c|}{ Early reflexes } & \multirow[t]{2}{*}{ Late reflexes } \\
\hline & & Right & Left & \\
\hline Normal latency values & & \multicolumn{2}{|c|}{$\begin{array}{l}10.6 \pm 2.5 \mathrm{msec} \\
\text { Difference between } \\
\text { right and left sides } \\
\text { less than } 1.2 \mathrm{msec}\end{array}$} & $\begin{array}{l}\text { Ipsilateral } 31 \pm 10 \mathrm{msec} \\
\text { Contralateral } 32 \pm 11 \mathrm{msec} \\
\text { Difference between ipsilateral } \\
\text { and contralateral responses } \\
\text { less than } 5 \mathrm{msec}\end{array}$ \\
\hline Supratentorial & $\begin{array}{c}1-17 \\
18 \\
19 \\
20-\mathrm{A} \\
20-\mathrm{B} \\
21\end{array}$ & $\begin{array}{l}\text { Normal } \\
\text { Normal } \\
\text { Normal } \\
\text { Normal } \\
\text { Absent } \\
22 \cdot 7 \mathrm{msec}\end{array}$ & $\begin{array}{l}\text { Normal } \\
\text { Normal } \\
\text { Normal } \\
\text { Normal } \\
\text { Absent } \\
16 \cdot 7 \mathrm{msec}\end{array}$ & $\begin{array}{l}\text { Indeterminate or absent } \\
\text { Absent } \\
\text { Absent } \\
\text { Absent } \\
\text { Absent } \\
\text { Absent }\end{array}$ \\
\hline Primary brain-stem lesions & $\begin{array}{l}22 \\
23 \\
24 \\
25-\mathrm{A} \\
25-\mathrm{B}\end{array}$ & $\begin{array}{l}\text { Absent } \\
\text { Absent } \\
\text { Absent } \\
14 \cdot 1 \mathrm{msec} \\
\text { Normal }\end{array}$ & $\begin{array}{l}\text { Absent } \\
\text { Absent } \\
\text { Absent } \\
\text { Absent } \\
\text { Absent }\end{array}$ & $\begin{array}{l}\text { Absent } \\
\text { Absent } \\
\text { Absent } \\
\text { Absent } \\
\text { Left efferent block }\end{array}$ \\
\hline Anoxia & $\begin{array}{l}26 \\
27\end{array}$ & $\begin{array}{l}\text { Absent } \\
\text { Absent }\end{array}$ & $\begin{array}{l}\text { Absent } \\
\text { Absent }\end{array}$ & $\begin{array}{l}\text { Absent } \\
\text { Absent }\end{array}$ \\
\hline Metabolic-toxic & $\begin{array}{l}28-A \\
28-B \\
29-A \\
29-B \\
30-48\end{array}$ & $\begin{array}{l}\text { Absent } \\
\text { Normal } \\
\text { Absent } \\
\text { Normal } \\
\text { Normal }\end{array}$ & $\begin{array}{l}\text { Absent } \\
\text { Normal } \\
\text { Absent } \\
\text { Normal } \\
\text { Normal }\end{array}$ & $\begin{array}{l}\text { Absent } \\
\text { Normal (after recovery from coma) } \\
\text { Absent } \\
\text { Normal (after recovery from coma) } \\
\text { Indeterminate or absent }\end{array}$ \\
\hline
\end{tabular}

stimulated at the supraorbital foramen eliciting the ipsilateral early and the bilateral late reflex responses (Fig. 1). If no response is evoked with single shocks of $50-150 \mathrm{~V}$ and $0 \cdot 1-1.0 \mathrm{msec}$ duration, paired stimuli of $150 \mathrm{~V}$ and $1.0 \mathrm{msec}$ duration with $5 \mathrm{msec}$ interval are utilized.

Forty-eight comatose (absence of any response to verbal or noxious stimuli) and semicomatose (nonpurposeful reflex or withdrawal motor response to noxious stimuli) patients were studied. Results of orbicularis oculi reflex testing (Table) were compared with clinical assessments of brain-stem function (pupillary, oculocephalic, oculovestibular, corneal, and gag reflexes). Post-mortem examination of 11 of 17 patients who died included preparation of serial $3 \mathrm{~mm}$ thick blocks of the mesencephalon, pons, and medulla. Multiple 5-20 $\mu$ thick sections from each block were examined microscopically utilizing a battery of stains.

\section{RESULTS}

Of 48 cases included in this study, coma was due to supratentorial lesions in 21 , brain-stem lesions in four, anoxia in two, and metabolic encephalopathy or drug intoxication in 21 .
SUPRATENTORIAL LESIONS Of the 21 cases with supratentorial lesions (16 neoplasms, two abscesses, two haemorrhages, and one infarct), cases 1 to 17 (15 neoplasms and two abscesses) had varying degrees of central facial paresis and hemiparesis with preservation of clinically elicitable brain-stem reflexes. Orbicularis oculi reflex studies showed uniform findings in all cases. The early reflexes were normal bilaterally, while the late reflexes were absent or of such minimal amplitude as to be indistinguishable from the baseline (Fig. 2). Post mortem examination in two instances (cases 1 and 2) confirmed supratentorial mass lesions and demonstrated no gross or microscopic abnormalities of the brainstem.

In two subjects (cases 18 and 19) supratentorial lesions were complicated by signs of unilateral uncal herniation causing ipsilateral oculomotor nerve paresis in addition to contralateral central facial paresis and hemiparesis. The contralateral pupillary reflex and reflex ocular movement and the bilateral corneal and gag reflexes were preserved. In both cases, the early orbicularis re- 


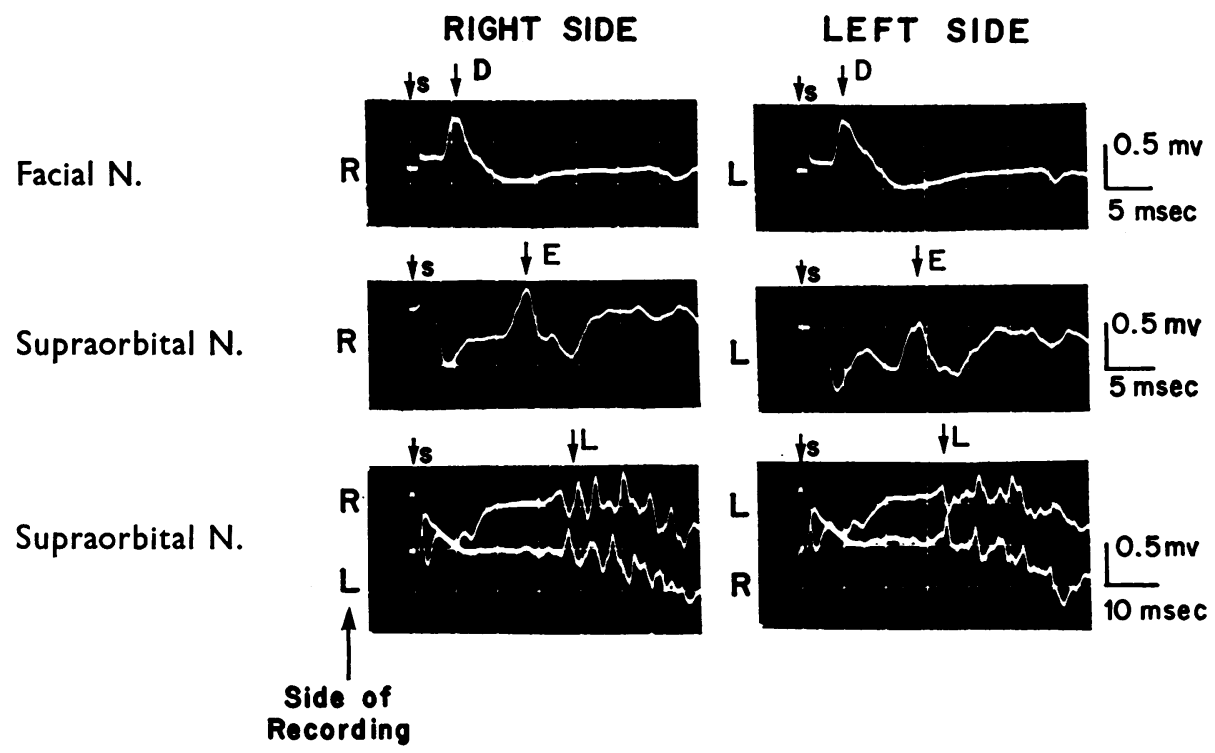

FIG. 1. Normal orbicularis oculi reflex showing: direct response to facial nerve stimulation (D); ipsilateral early reflex response to supraorbital nerve stimulation (E); and bilateral late reflex responses to supraorbital nerve stimulation (L). Stimulation artefact (s).

Facial $\mathbf{N}$.

Supraorbital N.

Supraorbital N.
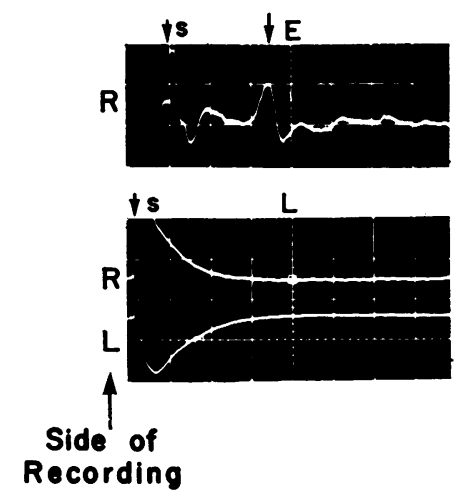

LEFT SIDE
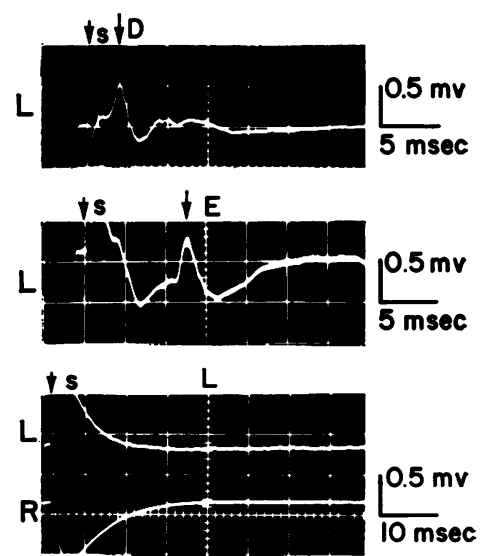

FIG. 2. Representative orbicularis oculi reflex in coma due to supratentorial lesions (cases 1-17) or metabolic-toxic encephalopathy (cases 30-48) showing: normal early reflexes (E) and absent late reflexes (L). Stimulation artefact (s). 
CASE RIGHT SIDE

18

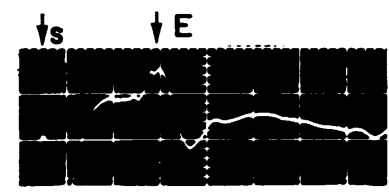

19
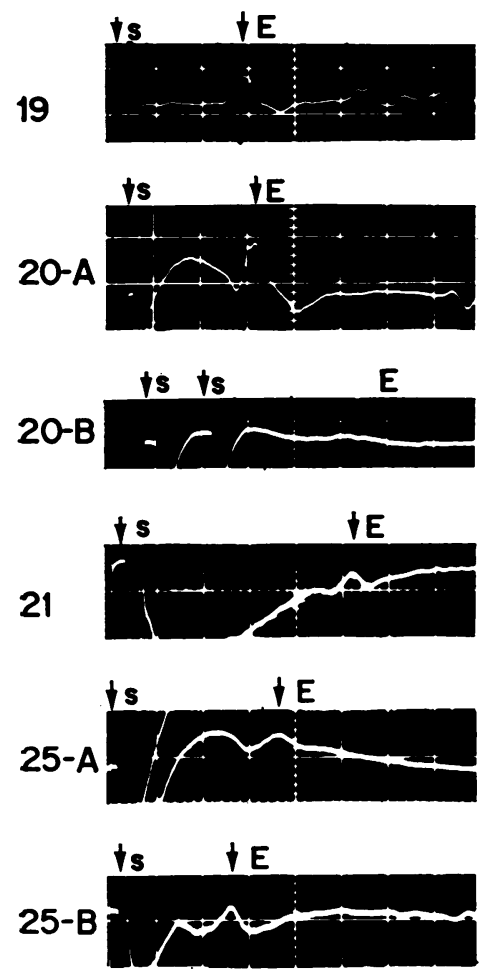
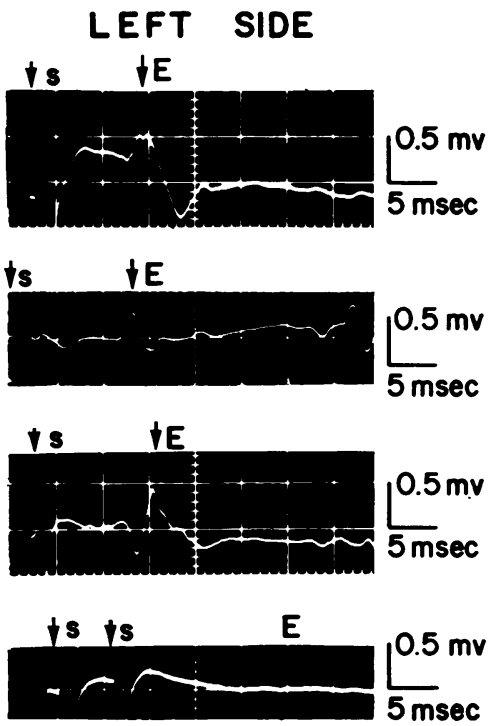

FIG. 3. Right and left early reflexes $(\mathrm{E})$ in cases $18-21$ and 25 (see text). Stimulation artefact (s).
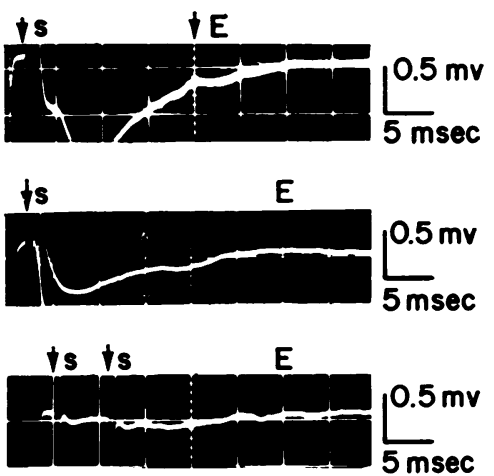

flexes were normal bilaterally (Fig. 3) and the late reflexes were absent. Necropsy revealed massive hemispheric infarction due to internal carotid artery thrombosis in one (case 18) and a ruptured aneurysm with intracerebral haemorrhage in the other (case 19). In both cases, cerebral oedema with uncal herniation ipsilateral to the supratentorial lesion was demonstrated with no gross or microscopic evidence of brainstem damage.

In one subject (case 20), a bilateral supratentorial glioblastoma was complicated by signs of transtentorial herniation. An initial orbicularis oculi reflex study performed when examination revealed coma with quadriparesis but preserved clinical brain-stem reflexes showed a normal early reflex bilaterally (20-A in Fig. 3) with absent late reflexes. Repeat study of orbicularis oculi reflexes after transtentorial herniation with associated absence or marked di minution of all clinical brain-stem reflexes showed the early reflex to be no longer present on either side (20-B in Fig. 3). The late reflexes remained absent. Necropsy confirmed bilateral transtentorial herniation with secondary Duret haemorrhages in the mesencephalon and rostral pons (Fig. 4). Microscopic examination revealed oedema of the entire mesencephalon, pons, and medulla. The mesencephalic nucleus of the trigeminal nerve was involved directly by the Duret haemorrhages, while the main sensory and motor trigeminal nuclei in the pons and the spinal tri- 
geminal tract and nucleus in the medulla were involved only with oedema.

In another subject (case 21), a supratentorial intracerebral haemorrhage was complicated by signs of ipsilateral uncal herniation requiring emergency neurosurgical decompression. The patient remained comatose with markedly depressed brain-stem reflexes. Orbicularis oculi reflex study performed three weeks postoperatively showed a delayed early reflex bilaterally (Fig. 3) and absent late reflexes. Necropsy showed extension of thalamic haemorrhage into the mesencephalon terminating at the caudal level of the superior colliculus with resolving

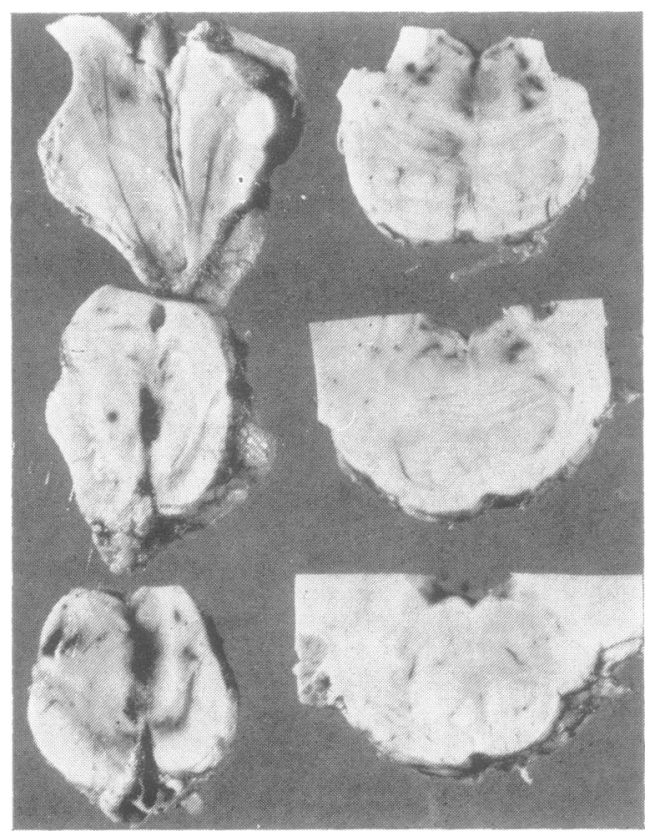

FIG.4. Case 20. Duret haemorrhages in mesencephalon and rostral pons.

Duret haemorrhages of the mesencephalon and rostral pons. Microscopic examination showed destruction of the mesencephalic trigeminal nucleus and oedema and infarction of the motor, sensory, and spinal trigeminal nuclei and tracts.

PRIMARY BRAIN-STEM LESIONS Of the four cases with primary brain-stem lesions (three haemor- rhages and one infarct), cases 22 and 23 were $\frac{0}{\bar{c}}$ young adults with chronic uraemia. Both de- $Z$ veloped haemorrhagic diatheses and hyperten- $\stackrel{\circ}{=}$ sion and both experienced an abrupt onset of coma with pinpoint pupils and loss of all clinic- $\frac{\overline{0}}{0}$ ally elicitable brain-stem reflexes. In both, the early and the late orbicularis oculi reflexes were

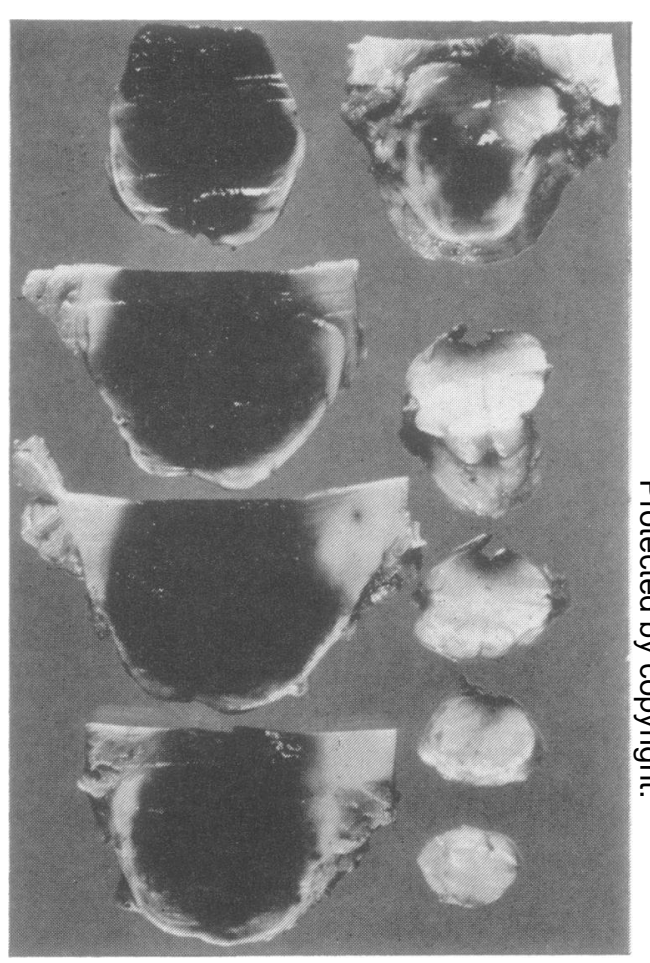

FIG. 5. Case 22. Massive brain-stem haemorrhage with $\stackrel{\overbrace{}}{\stackrel{\circ}{\Rightarrow}}$ almost total destruction of mesencephalon and ponso음 (mesencephalon not illustrated in the photograph).

absent. Necropsy revealed massive haemorrhagẹ. into the mesencephalon and pons in both cases (Fig. 5) with destruction of the mesencephalic, motor, and sensory trigeminal nuclei and? oedematous involvement of the spinal trigemina ${ }_{0}$ nucleus and tract.

One subject (case 24) was a diabetic woman? who developed signs of basilar artery thrombosis with diplopia and dysarthria followed in two ${ }^{\circ}$ hours by coma with pinpoint pupils and loss of 
all clinical brain-stem reflexes. The early and the late orbicularis reflexes were absent.

Another subject (case 25) was a hypertensive woman who abruptly developed signs of a leftsided pontine lesion. Examination showed right hemiplegia with a left peripheral facial palsy. There was minimal withdrawal response of the left extremities to noxious stimuli. Pupils were pinpoint with minimal reaction to light. Oculocephalic and oculovestibular reflexes were absent. The corneal reflex was diminished on the right and absent on the left. The gag reflex was diminished. The early orbicularis reflex was absent on the left and delayed on the right (25-A in Fig. 3). The late reflexes were absent. The patient gradually made a remarkable recovery. At discharge, she was able to walk despite a moderate right hemiparesis. A moderate left peripheral facial paresis, paralysis of conjugate gaze to the left, and internuclear ophthalmoplegia evident on right lateral gaze were the only other residual deficits. The left early orbicularis reflex remained absent, while the right early reflex had returned to normal (25-B in Fig. 3). The late reflex on the left side was absent, while the late reflex on the right side was normal regardless of the side of supraorbital nerve stimulation (left efferent block) indicating the involvement of the left facial nucleus.

ANOXIA In two subjects (cases 26 and 27) with acute renal failure, initial studies, when the patients were mildly obtunded but without other deficit, showed the early orbicularis reflexes to be normal. Subsequently, both patients experienced cardiorespiratory arrest requiring resuscitative measures. In neither case was adequate spontaneous respiration restored and artificial respirator assistance (case 26) or maintenance (case 27) was required. Both patients were comatose with dilated fixed pupils with no clinically elicitable brain-stem reflexes. Electroencephalograms showed diffuse low voltage slow activity in one instance (case 26) and an isoelectric record in the other (case 27). Repeat orbicularis oculi reflex study showed the early and late reflexes to be absent bilaterally in both cases. Necropsy in case 26 revealed no gross brain-stem abnormalities but microscopy demonstrated severe homogenizing necrosis of neurones throughout the brainstem.
METABOLIC-TOXIC Twenty-one cases with metabolic or toxic coma (eight uraemic and two hepatic coma, seven barbiturate and three glutethimide intoxication, and one carbon monoxide poisoning) were studied. Clinically elicitable brain-stem reflexes and spontaneous respiration in cases 28 (barbiturate intoxication) and 29 (glutethimide intoxication) were initially absent or severely impaired but later recovered. In these, the early and late orbicularis reflexes were initially absent (28-A and 29-A in Table), but returned to normal (28-B and 29-B in Table) as the patients eventually made complete recovery. In the other 19 (cases 30-48) with preserved clinical brain-stem reflexes and spontaneous respiration, the early orbicularis reflexes were normal but the late reflexes were either absent or of minimal amplitude (Fig. 2). Post mortem examination in two cases (case 30-uraemia; case 31 -carbon monoxide poisoning) showed no brain-stem abnormalities.

\section{DISCUSSION}

We have postulated that alteration of the early component of the orbicularis oculi reflex is relatively specific for pontine lesions and that the absence of the late component in comatose patients reflects a diffuse suppression of the multisynaptic reticular system rather than a specific or local block in the brain-stem. The results recorded above are consistent with this view. The late orbicularis reflex was absent or of minimal amplitude regardless of the aetiology of coma in all 48 cases including six with negative gross and microscopic examinations of the brainstem. The early orbicularis reflex, on the other hand, was normal in coma due to supratentorial mass lesions without clinical (15 cases) or pathological (two cases) evidence of transtentorial herniation. In the two instances of supratentorial lesions with unilateral uncal herniation and oculomotor nerve paresis, the early reflexes were also unaltered, suggesting the integrity of the pons as later verified at post mortem examination in both cases. In the presence of more severe transtentorial herniation with pathological confirmation of Duret haemorrhages in the pons (two cases), the early reflexes were either abolished or delayed. In coma due to primary brainstem haemorrhage, infarction, or anoxia (six 
cases, with pathological verification in three), the early reflexes were also abolished or delayed. Integrity of the pons in 19 instances of metabolic or toxic coma of various causes was documented by normal early reflexes bilaterally and verified pathologically in two cases. The initial absence of early reflex in two cases of severe barbiturate and glutethimide intoxication, respectively, presumably represents a reversible functional or pharmacophysiological block as evidenced by the recovery of the early reflex configurations concomitant with the patients' improvement.

Maurice W. Van Allen, Professor, Department of Neurology, assisted in the preparation of this manuscript.

\section{REFERENCES}

Bender, L. F., Maynard, F. M., and Hastings, S. V. (1969). The blink reflex as a diagnostic procedure. Archives of Physical Medicine, 50, 27-31.

Gandiglio, G., and Fra, L. (1967). Further observations on facial reflexes. Journal of the Neurological Sciences, 5, 273285.

Kimura, J. (1970). Alteration of the orbicularis oculi reflex by pontine lesions. Study in multiple sclerosis. Archives of Neurology, 22, 156-161.

Kimura, J. (1971). An evaluation of the facial and trigeminal nerves in polyneuropathy: electrodiagnostic study in Charcot-Marie-Tooth disease, Guillain-Barré syndrome, and diabetic neuropathy. Neurology (Minneap.), 21, 7 752.

Kimura, J. (1971). Electrodiagnostic study of brainstę․ strokes. Stroke, 2, 576-586.

Kimura, J., and Lyon, L. W. (1972). Orbicularis oculi re in the Wallenberg syndrome: alteration of the late refex by lesions of the spinal tract and nucleus of the trigemffal nerve. Journal of Neurology, Neurosurgery, and Psychiat 35, 228-233.

Kimura, J., and Lyon, L. W. (1972). Electrodiagnostic stưy of posterior fossa lesions. Alteration of orbicularis og̣li reflex in brainstem, cerebellar, and cerebello-pontine ande tumors and syringes. (In preparation.)

Kimura, J., Powers, J. M., and Van Allen, M. W. (19 $\overrightarrow{6 \overrightarrow{6}})$. Reflex response of orbicularis oculi muscle to supfaorbital nerve stimulation. Study in normal subjects andan peripheral facial paresis. Archives of Neurology, 21, 19. 199.

Kimura, J., Rodnitzky, R. L., and Van Allen, M. W. (19 70 ). Electrodiagnostic study of trigeminal nerve. Orbiculatis oculi reflex and masseter reflex in trigeminal neuralgoa, paratrigeminal syndrome, and other lesions of the trigeminal nerve. Neurology (Minneap.), 20, 574-583.

Kugelberg, E. (1952). Facial reflexes. Brain, 75, 385-396. $\overrightarrow{\vec{\omega}}$

Namerow, N. S., and Etemadi, A. (1970). The orbiculäj oculi reflex in multiple sclerosis. Neurology (Minneap.), 20 , 1200-1203.

Rushworth, G. (1962). Observations on blink reflexes. Journal of Neurology, Neurosurgery, and Psychiatry, Ф5, 93-108.

Shahani, B. (1970). The human blink reflex. Journig Neurology, Neurosurgery, and Psychiatry, 33, 792-80 $\mathrm{N}$

Tokunaga, A., Oka, M., Murao, T., Yokoi, H., Okumug, 9 , Hirata, T., Miyashita, Y., and Yoshitatsu, S. (1958 An experimental study on facial reflex by evoked electomyography. Medical Journal of Osaka University, 9, 3n411. 